\title{
Non-Radiating Edge Gap Coupled Capsule-Shaped and Nose-Shaped Microstrip Antennas for 3G Applications
}

\author{
Pratigya Mathur, Manisha Chattopadhyay, and Girish Kumar
}

\begin{abstract}
Two novel configurations for increasing the impedance bandwidth of the microstrip patch antennas have been proposed for operating in the $3 \mathrm{G}$ mobile communication range. In these configurations, additional resonators of semicircular shape rather than conventional rectangle are gap coupled to the non-radiating edges of the fed rectangular patch. A comparative study is done between the antennas of the same size with two semicircular parasitic patches and an antenna having a combination of semi-circular and rectangular parasitic patches. Compared to the available broadband antennas, the proposed antenna structure gives a better bandwidth.
\end{abstract}

Index Terms-Gap coupling, microstrip antennas, 3G, VSWR.

\section{INTRODUCTION}

$3 \mathrm{G}$ wireless mobile system is popular mainly due to its wide bandwidth characteristic that supports higher data transmission rates. The broadband feature requires a Microstrip Antenna (MSA) to be designed to overcome its normal limitation of a narrow bandwidth. The bandwidth of microstrip patch antennas can be increased considerably by including two additional resonators gap-coupled to the radiating as well as non-radiating edges of a rectangular patch antenna.

There is several works that report the shape of the additional resonators as well as the fed patch of the nonradiating gap coupled microstrip antennas to be same. In [1], [2], [3] the conventional rectangular fed patches have been gap coupled and hybrid coupled to the similar rectangular parasitic patches. The circular, semi-circular and triangular shaped patches have also been edge gap coupled to the similar shaped parasitic patches [4]-[6]. In this work, two new configuration have been proposed having a combination of different shapes of the parasitic patches. A non-radiating gap coupled antenna having fed rectangular patch with two semi-circular parasitic patches that resembles a shape of the capsule is proposed .This antenna is called as Capsule-Shaped Antenna. Another proposed configuration has rectangular fed patch with combination of rectangular and semi-circular shape of the parasitic patches resembling

Manuscript received January 2, 2013; revised May 10, 2013.

F. P. Mathur is with Ph.D research scholar at Indian Institute of Technology, Bombay, Powai, Mumbai, India (e-mail: pratigya.mathur@ gmail.com).

S. M. Chattopadhyay is with Vivekanand Education Society's Institute of Technology, University of Mumbai, India (e-mail: m.chatterjee@rediffmail.com).

T. G. Kumar is with Department of Electrical Engineering Indian Institute of Technology, Bombay, Powai, Mumbai, India (e-mail: gkumar@ ee.iitb.ac.in). the nose of a missile and hence, known as Nose-Shaped broadband Microstrip Antenna (MSA).The proposed antenna design is simple in construction. The length, width of the patch, position of the co-axial feed and gap between the patches play an important role in increasing the bandwidth. The parasitic patches placed on the two nonradiating side of the fed rectangular patch get excited through the coupling with fed patch. The variation of resonant frequencies of the resonators yields broader bandwidth. If the resonance frequencies of these three patches are close to each other, then broad bandwidth is obtained. A non-radiating gap coupled MSA patch antenna is proposed on a substrate with $\varepsilon r=2.33, \tan \delta=0.0009$ and $h=3.45 \mathrm{~mm}$. This patch is fed by the coaxial probe to obtain a $50 \mathrm{ohm}$ input impedance. Such an antenna occupies less space and can be used to replace rectangular, triangular and circular patch antenna that occupies a greater space.

\section{Design Methodology}

\section{A. Antenna Design}

This paper presents design of a small and thin sized antenna with specifications desired for $3 \mathrm{G}$ system applications. The antenna is required to operate at the transmitting band of $2.11 \mathrm{GHz}$ to $2.17 \mathrm{GHz}$ with $\mathrm{VSWR} \leq 2$ of 3 Gfrequency range. This type of antenna can be used for RF Energy Harvesting and transmitting tower radiation level detector as well. The proposed antenna having frequency mentioned above can be used as a $3 \mathrm{G}$ Jammer.

In the gap coupled patch antenna, the patch placed close to the fed patch gets excited through the coupling between the two patches. Such a patch is known as a parasitic patch. If the resonance frequencies of these two patches are close to each other, then broadband is obtained. The overall input VSWR will be the superposition of the responses of the two resonators resulting in a wide $\mathrm{BW}$. Due to the coupling between the two patches, a loop is observed in the impedance plot of RMSA. Also, the maximum BW is obtained when the loop in the impedance plot is completely inside the VSWR=2 circle and its size is as large as possible. The gap between the fed and the parasitic patches in the non-radiating edge coupled RMSA is small as compared to radiating edges because the field varies sinusoidally along the non-radiating edge so the coupling is small as compared to the coupling along the radiating edge [3].

In this paper, a non-radiating gap coupled capsule shaped MSA is analyzed and compared with nose -shaped antenna. Both of these antenna can be easily used at the places where space needs to be saved by providing the rounded edges.

The capsule shaped antenna has been optimized with 
length of fed rectangular patch as $46 \mathrm{~mm}$ and width as 20 $\mathrm{mm}$ which is coaxially fed at $8.85 \mathrm{~mm}$ to achieve $50 \mathrm{ohm}$ impedance matching. The radius of semi-circular parasitic patch is $25 \mathrm{~mm}$ and the gap between fed and parasitic patch is $3.5 \mathrm{~mm}$. The nose-shaped antenna has been optimized with same dimensions as that of the capsule-shaped antenna. The length of fed patch is $46 \mathrm{~mm}$ and width is $20 \mathrm{~mm}$ which is fed at $8 \mathrm{~mm}$ to achieve $50 \mathrm{ohm}$ impedance matching. The radius of semi-circular parasitic patch is $25 \mathrm{~mm}$ and rectangular parasitic patch has length of $46 \mathrm{~mm}$ and width of $25 \mathrm{~mm}$ and the gap between fed and parasitic patch is $3.5 \mathrm{~mm}$. Hence the overall width of both the antennas is same.

The antennas have been optimized for higher band width and gain by varying the length, width, position of the coaxial feed and gap between the patches. The simulated performances were obtained by using Zeland's IE3D software [7] for RMSA. Fig. 1 (a) \& (b) show the structure of the capsule- shaped and nose- shaped antenna.
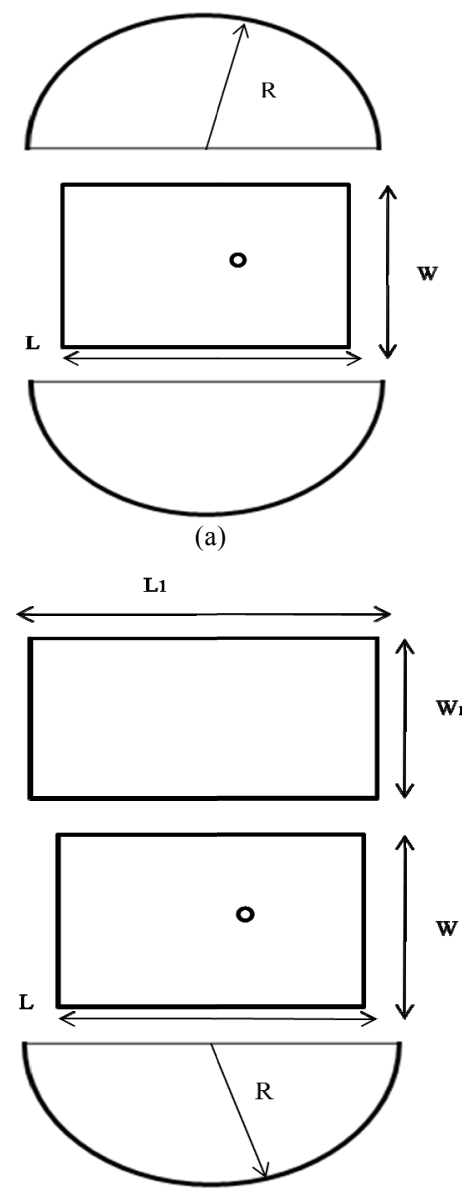

(b)

Fig. 1. Non radiating edge gap coupled antenna (a) Capsule Shaped antenna (b) Nose Shaped antenna.

\section{RESULTS}

The capsule- shaped antenna and nose-shaped antenna have been designed and simulated using IE3D [7]. The Input Impedance and VSWR Plot for capsule shaped antenna have been shown in Fig. 3 (a) \& (b) respectively and the radiation pattern and Gain Vs. Frequency plot in (c) \& (d) respectively. The plots for Nose-shaped antenna are shown in Fig. 4. The bandwidth of capsule-shaped antenna is 160 $\mathrm{MHz}$ with frequency from 2.04 to $2.20 \mathrm{GHz}$ while noseshaped antenna is $210 \mathrm{MHz}$ with frequency from 2.03 to $2.24 \mathrm{GHz}$. The wide bandwidth of the nose- shaped antenna has been obtained due to greater difference in resonance frequency of semi-circular and rectangular parasitic patches. However, a small difference in gain has been observed with maximum value of $7.20 \mathrm{~dB}$ at $2.20 \mathrm{GHz}$ for capsule-shaped antenna and $7.38 \mathrm{~dB}$ at $2.16 \mathrm{GHz}$ for nose -shaped antenna. Hence, both the proposed antennas operate well in the $3 \mathrm{G}$ band of frequency. With both the antennas having the same dimensions, the nose-shaped antenna has much greater band with as compared to the capsule-shaped antenna.

These antennas are compared to non-radiating edge gap coupled Rectangular MSA(RMSA) having bandwidth of $134 \mathrm{MHz}$ operating in the frequency range of 2.05 to $2.18 \mathrm{GHz}$ [8]. The maximum gain of $8.57 \mathrm{~dB}$ has been observed at $2.10 \mathrm{GHz}$. It can be clearly observed that it has much greater size than capsule- shaped and nose-shaped antenna.

TABLE I: COMPARISON OF BW AND GAIN OF DIFFERENT ANTENNAS
\begin{tabular}{|c|c|c|}
\hline Configuration & $\begin{array}{c}\text { Bandwidth } \\
(\mathrm{MHz})\end{array}$ & Gain(dB) \\
\hline $\begin{array}{c}\text { Nose shaped } \\
\text { antenna }\end{array}$ & 210 & 7.38 \\
\hline $\begin{array}{c}\text { Capsule shaped } \\
\text { antenna }\end{array}$ & 160 & 7.20 \\
\hline $\begin{array}{c}\text { Rectangular } \\
\text { Antenna }\end{array}$ & 134 & 8.57 \\
\hline
\end{tabular}

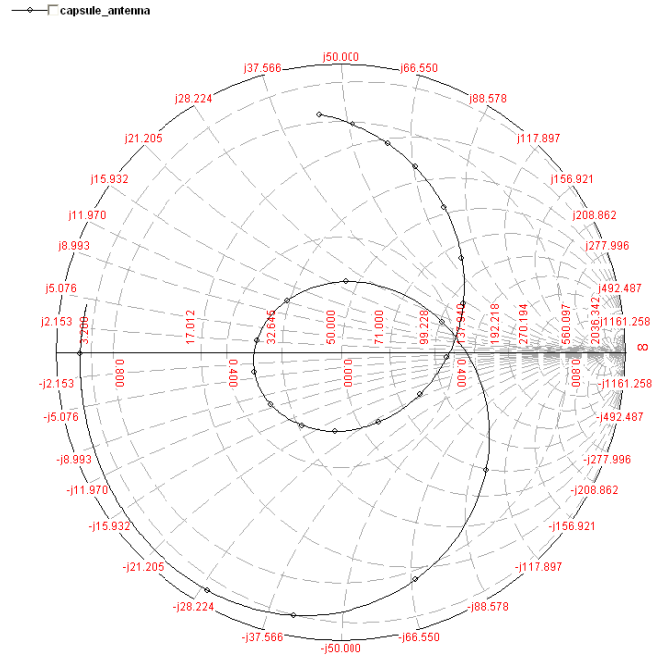

(a)

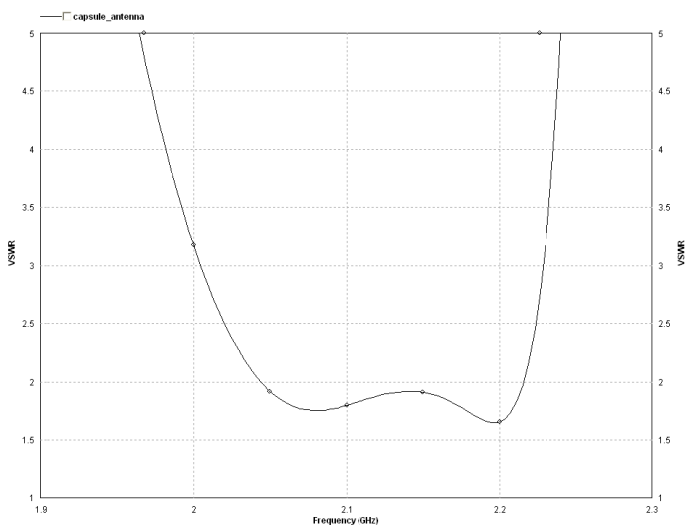

(b) 


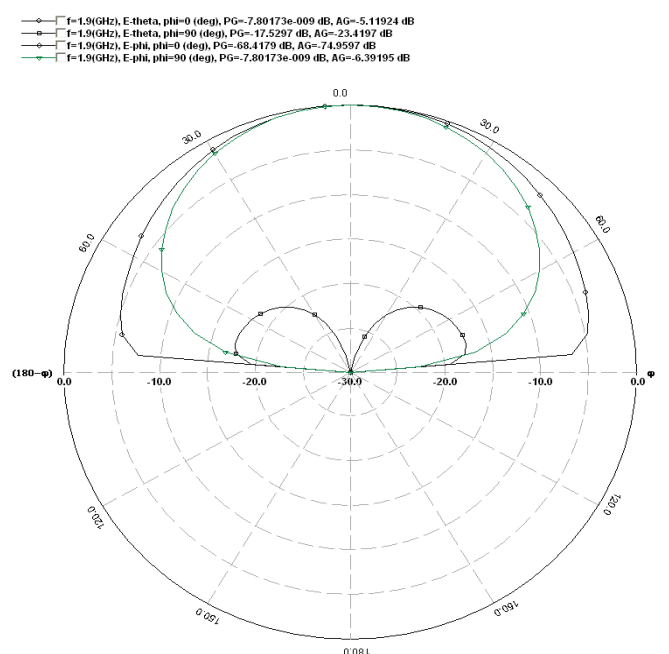

(c)

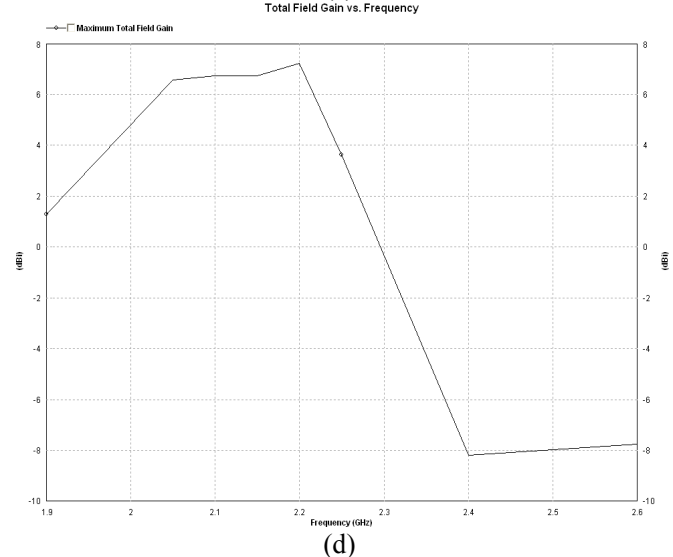

Fig. 2. Capsule- shaped antenna. (a) Input Impedance Plot (b) VSWR Plot (c) Radiation Pattern (d) Gain Vs. Frequency Plot.

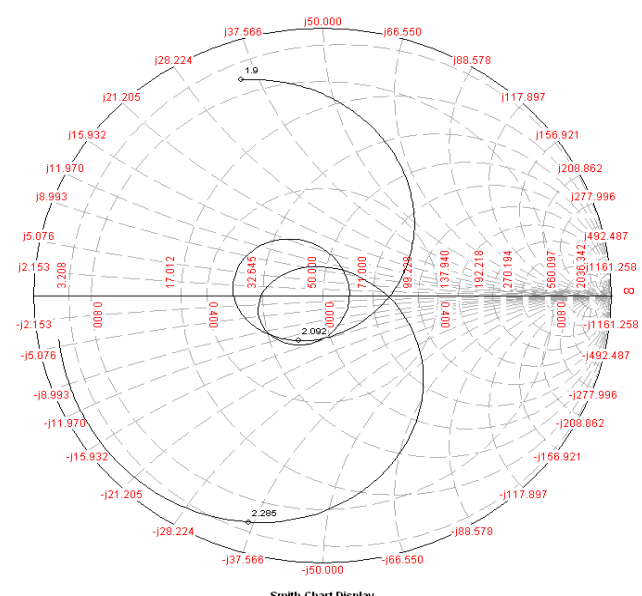

(a)

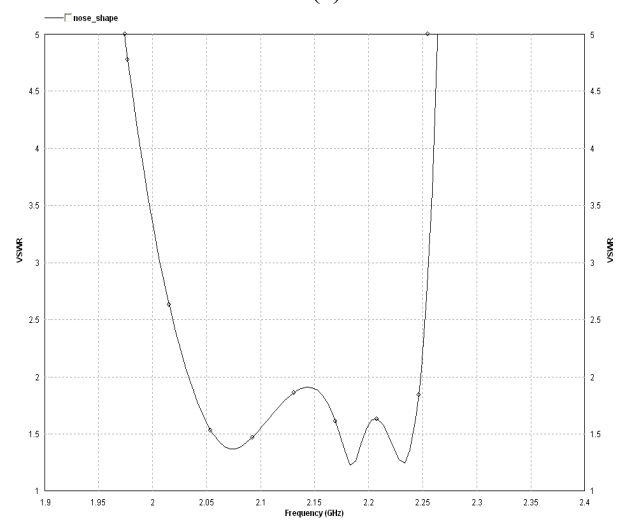

(b)

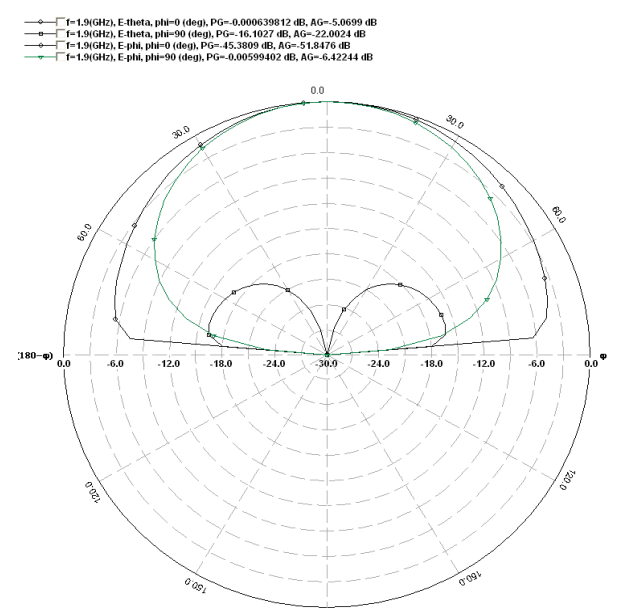

(c)

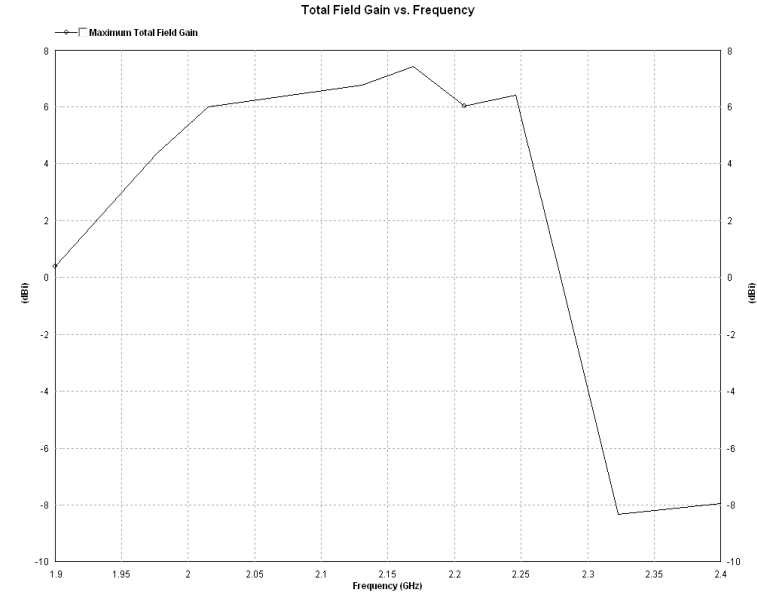

(d)

Fig. 3. Nose-shaped antenna.(a) Input impedance plot (b)VSWR plot (c)Radiation pattern(d)Gain Vs.frequency plot.

\section{CONCLUSION}

The proposed antennas structure achieved good bandwidth and gain for operation in the $3 \mathrm{G}$ band of frequency. The bandwidth and gain of three antennas presented in Table I. Hence, after comparing the three designs of antenna structure operating in the $3 \mathrm{G}$ band it is concluded that with the same size of the capsule-shape and nose-shaped antenna, the nose shaped antenna provided $31.25 \%$ greater bandwidth and greater gain. RMSA occupied up to $40 \%$ larger space and provided less bandwidth as compared to the two new proposed designs. Hence, the new proposed design occupy less area and provide larger bandwidth and gain and can be easily used at the places where space is to be saved by providing the rounded edges .It helps in providing miniaturization to the several wireless devices used these days.

\section{REFERENCES}

[1] G. Kumar and K. Gupta, "Nonradiating edges and four edges gapcoupled multiple resonator broad-band microstrip antennas," IEEE Transactions on Antennas and Propagation, vol. 33, no. 2, pp. 173178, Feb. 1985.

[2] G. Kumar and K. Gupta, "Directly coupled multiple resonator wideband microstrip antennas," IEEE Transactions on Antennas and Propagation, vol. 33, no. 6, pp. 588- 593, Jun 1985.

[3] G. Kumar and K. P. Ray, Broadband Microstrip Antennas, Artech House Inc., 2003. 
[4] K. P. Ray and G. Kumar, "Multi-frequency and broadband hybrid coupled circular microstrip antennas," Electronics Letters, vol. 33, no. 6, pp. 437-438, 13 Mar 1997.

[5] M. B. Nile, A. A. Rasheed, and G. Kumar, "Broadband Gap-Coupled Semicircular and Triangular Microstrip Antennas," IEEE AP-S Int. Symp. Digest, pp. 1202-1205, July 1994.

[6] P. S. Bhatnagar et al., "Hybrid Edge Gap and Directly Coupled Triangular Microstrip Antenna," Electronics Letters, vol. 22, no. 16, pp. 853-855, 1986

[7] Zeland IE3D software. [Online]. Available: http://www.zeland.com

[8] P. Mathur, G. Kumar, and M. Chattopadhyay, "Non-radiating gap coupled Rectangular Microstrip Antenna for 3G Applications," International Conference on Microwave, Antenna, Propagation and Remote Sensing(ICMARS),December2011.

[9] K. P. Ray, V. Sevani, A A. Deshmukh, "Compact Gap-coupled Microstrip Antennas for Broadband and Dual Frequency Operations," International Journal of Microwave and Optical Technology, vol. 2, no. 3, July 2007.

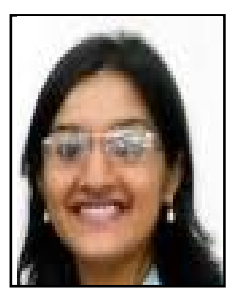

Pratigya Mathur is currently a Ph.D research scholar at Indian institute of technology bombay. She has completed her B.E \& M.E in electronics \& communications in 2012. Her research interests are microstrip antennas, RF and microwaves.

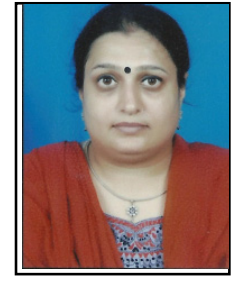

Manisha Chattopadyay is an associate professor at vivekananda education society's Institute of Technology, Chembur, Mumbai and has 15 years of teaching experience in the areas of Microwaves, Electromagnetics, Fibre optics. She completed her B. Tech and M. Tech from Calcutta University and is currently pursuing $\mathrm{PhD}$ from Calcutta University in the area of Photonics and Opto electronics.

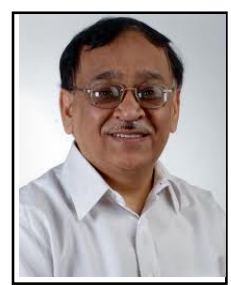

Girish Kumar is a professor at Indian Institute of technology bombay and has 30 years of experience in designing antennas and microwave circuits. He has published more than 200 papers in the national and international journals and conference proceedings. He has also written a book entitled "Broadband Microstrip Antennas" published by Artech House, USA in 2003 